\title{
Vertical profiles of microphysical particle properties derived from inversion with two-dimensional regularization of multiwavelength Raman lidar data: experiment
}

\author{
Detlef Müller, ${ }^{1, *}$ Alexei Kolgotin, ${ }^{3}$ Ina Mattis, ${ }^{2}$ Andreas Petzold, ${ }^{4}$ and Andreas Stohl ${ }^{5}$ \\ ${ }^{1}$ Gwangju Institute of Science and Technology (GIST), 1 Cheomdan-Gwagiro (Oryong-dong), Gwangju 500-712, South Korea \\ ${ }^{2}$ Leibniz Institute for Tropospheric Research (IfT), Permoserstraße 15, 04318 Leipzig, Germany \\ ${ }^{3}$ Physics Instrumentation Center, Troitsk, Moscow Region, 142190, Russia \\ ${ }^{4}$ Deutsches Zentrum für Luft- und Raumfahrt (DLR), Institut für Physik der Atmosphäre, \\ Oberpfaffenhofen, 82234 Wessling, Germany \\ ${ }^{5}$ Norwegian Institute for Air Research (NILU), P.O. Box 100, 2027 Kjeller, Norway \\ ${ }^{*}$ Corresponding author: detlef@tropos.de
}

Received 23 August 2010; revised 2 February 2011; accepted 11 February 2011; posted 16 February 2011 (Doc. ID 133847); published 9 May 2011

\begin{abstract}
Inversion with two-dimensional (2-D) regularization is a new methodology that can be used for the retrieval of profiles of microphysical properties, e.g., effective radius and complex refractive index of atmospheric particles from complete (or sections) of profiles of optical particle properties. The optical profiles are acquired with multiwavelength Raman lidar. Previous simulations with synthetic data have shown advantages in terms of retrieval accuracy compared to our so-called classical one-dimensional (1-D) regularization, which is a method mostly used in the European Aerosol Research Lidar Network (EARLINET). The 1-D regularization suffers from flaws such as retrieval accuracy, speed, and ability for error analysis. In this contribution, we test for the first time the performance of the new 2-D regularization algorithm on the basis of experimental data. We measured with lidar an aged biomass-burning plume over West/Central Europe. For comparison, we use particle in situ data taken in the smoke plume during research aircraft flights upwind of the lidar. We find good agreement for effective radius and volume, surface-area, and number concentrations. The retrieved complex refractive index on average is lower than what we find from the in situ observations. Accordingly, the single-scattering albedo that we obtain from the inversion is higher than what we obtain from the aircraft data. In view of the difficult measurement situation, i.e., the large spatial and temporal distances between aircraft and lidar measurements, this test of our new inversion methodology is satisfactory. (C) 2011 Optical Society of America OCIS codes: $\quad 010.0010,010.1100,010.1110,010.3640,120.0280$.
\end{abstract}

\section{Introduction}

This paper follows up on [1], which presents a theory for the inversion of lidar $\bar{d}$ ata with two-dimensional (2-D) regularization (or smoothing). This method is

0003-6935/11/142069-11\$15.00/0

(C) 2011 Optical Society of America used to infer profiles of microphysical properties of atmospheric particles from a set of profiles of particle backscatter and extinction coefficients. Twodimensional regularization means that we apply smoothing of the particle size distribution (PSD) that is to be inferred for a given optical input data set, which is regularization along the first dimension, and that we apply another smoothing constrain 
along the vertical dimension, which is regularization along the second dimension.

The optical data are collected with multiwavelength aerosol Raman lidar. This instrument type has evolved in the past 15 years into a reliable technology for quantifying microphysical parameters of particulate pollution, e.g., effective radius and singlescattering albedo. First inversion results derived with the classical methodology of inversion with regularization are presented by [2-5]. Since then, the methodology has been continuousty improved [6-11].

Many more multiwavelength Raman lidars have been developed in recent years. Most of the new lidar stations are operated by the European Aerosol Research Lidar Network (EARLINET) [12,13]. Some stations exist outside Europe, e.g., in South Korea $[14,15]$. In the near future, the first airborne multiwavelength lidar will become operational [16]. There are plans for space-borne multiwavelength aerosol lidars; see [17] and http://dsm.gsfc.nasa.gov/ace/index .html. The enormous amount of data that will come from such instrument platforms calls for unsupervised and near-real-time processing of optical data into microphysical data products. This strong demand for improved inversion methodologies is the motivation for developing the method that we denote as inversion with 2-D regularization (or smoothing).

In contrast to the classical one-dimensional (1-D) regularization method, the $2-\mathrm{D}$ method is intrinsically designed for inferring profiles of microphysical particle properties by inverting either complete or sections of profiles of optical data (combination of backscatter and extinction coefficients). The classical inversion method requires time-consuming data preprocessing, in which an operator has to identify the height sections that are most suitable for data inversion. This methodology, furthermore, requires timeconsuming postprocessing of the solution space. The classical regularization methodology thus needs a specialist who is familiar with the concept of ill-posed inverse problems $[18,19]$ and who possesses strong background knowledge in atmospheric aerosol physics to extract a reasonable physical solution space from the mathematical solution space that is found in the first step of data analysis.

The 2-D regularization technique reduces this time-consuming data processing considerably. Simulation studies carried out so far show that this methodology outperforms the inversion with classical regularization for the case of effective radius and number, surface-area, and volume concentrations; see Fig. 8 in [1]. We do not see any significant improvements regarding the retrieval accuracy of the complex refractive index; see Fig. 8 in [1]. However, we also have to state that both methodologies tend to overestimate parameters of the PSD, i.e., effective radius and number, surface-area, and volume concentrations. This overestimation may be caused by an inappropriate use of constraints as, for instance, the nonnegativity of PSDs, smoothness of the in- ferred PSDs, and the way we perform error estimation of the inversion results [3,4]. Alternative approaches of using constraints in the inversion of optical data may be found in $[\underline{7,}, \underline{8}, \underline{20}]$.

In addition to sensitivity studies that are intended to further improve our inversion technology, we need to validate/test our algorithm with experimental data. We need microphysical particle parameters measured with independent methods, which makes such comparison studies quite laborious in terms of work effort and experimental costs.

Raman signals are comparably weak. The inversion of multiwavelength Raman lidar data is therefore restricted to data acquired during nighttime measurements. Lidar data are affected by the socalled overlap effect [21], which means that, depending on instrument type, we cannot use data in the lowest few hundred meters above the instrument.

Airborne in situ measurements in the vicinity of the lidar station thus are the best way of collecting the necessary high-quality validation data. The aircraft should also carry a (one-wavelength) lidar that permits observing the horizontal and vertical layering of the investigated pollution plumes near the multiwavelength lidar ground station. We need to keep in mind that we have to average the optical signals of the ground-based measurements. In dependence of the laser power and the intensity of the Raman return signals, this may mean that data averaging times can be up to $1-2 \mathrm{~h}$. In view of such long data averaging times a lidar aboard the aircraft provides valuable information regarding optical and geometrical properties of the aerosol plume in a wider area around the ground-based system. These very high demands have so far resulted in collection of only two validation/comparison data sets since 1998 [22].

We present in this contribution one new case study. This measurement describes an aged biomassburning aerosol plume. We collected data by aircraft [23] in the same aerosol plume, but a few hundred kilometers upwind of our lidar station. As the measurements by lidar and aircraft were not collocated, the optical and microphysical properties of the pollution layer could have changed during the time of observation by aircraft and by the lidar, regardless of the fact that the transport path of the plume was from west to east over Europe.

However, as will be shown later, the two portions of the plume originated from the same source region in Canada. We assume that the intensive optical and microphysical particle properties did not vary significantly in this plume. Furthermore, the pollution plume was already well aged (several days of transport time) [23] when it arrived in the area where the airborne measurements (in West Europe) were carried out. We assume that the intensive particle properties, i.e., particle effective radius, complex refractive index, and single-scattering albedo, did not change significantly along the comparably short path from the area of the airborne measurements to 
the lidar station in Germany. However, we cannot exclude that the particle extensive properties, i.e., number, surface-area, and volume concentrations, changed during this transport. Despite these tradeoffs, we believe that a comparison between lidar and aircraft data is worthwhile and that it can show us to some extent the performance capabilities of the new methodology.

In Section 2, we briefly describe the methodology. The case study is described in Section 3. In Section 4, we present the comparison to the data that we $o \bar{b}$ tained from the airborne measurements. We close our contribution with a summary in Section $\underline{5}$.

\section{Methodology}

\section{A. Multiwavelength Lidar}

The optical data were collected with Multiwavelength Atmospheric Raman lidar for Temperature, Humidity, and Aerosol profiling (MARTHA) [24]. The multiwavelength lidar is installed in the main building of the Leibniz Institute for Tropospheric Research in Leipzig $\left(51.3^{\circ} \mathrm{N}, 12.4^{\circ} \mathrm{E}\right)$, Germany. The lidar is used for observations in the framework of EARLINET [12].

The instrument emits laser pulses at 355,532 , and $1064 \mathrm{~nm}$. From the elastically backscattered signals, and signals inelastically (Raman) scattered from nitrogen and water-vapor molecules, we determine particle volume backscatter coefficients at 355, 532, and $1064 \mathrm{~nm}$, and particle volume extinction coefficients at 355 and $532 \mathrm{~nm}[\underline{9}, 25]$. Particle extinctionto-backscatter (lidar) ratios at 355 and $532 \mathrm{~nm}$, and extinction-related (wavelength pair $355 / 532 \mathrm{~nm}$ ) and backscatter-related (wavelength pair $355 / 532 \mathrm{~nm}$ and 532/1064 nm) Ångström exponents follow automatically. The relative error (1 standard deviation) of the volume backscatter coefficients in the free troposphere ranges from $5 \%$ to $15 \%$. The relative errors of the extinction values are between $15 \%$ and $20 \%$. The absolute error of the extinction coefficients is $1.5-4 \mathrm{Mm}^{-1}\left(\mathrm{Mm}^{-1}=10^{6} \mathrm{~m}\right)$; see also [26].

The profile of relative humidity was computed from a radiosonde launch. The sonde was launched approximately $40 \mathrm{~km}$ to the northwest of Leipzig.

\section{B. Inversion with Two-Dimensional Regularization}

The methodology is explained in detail in [1]. Complete sections of profiles of backscatter and extinction coefficients are used as input to the algorithm. We solve the ill-posed inverse problem for the profiles of particle effective radius, profiles of number, surface-area, and volume concentrations, and profiles of the complex refractive index. From these profiles, we calculate profiles of the single-scattering albedo with a Mie-scattering algorithm [27].

Our experimental data are affected by the overlap effect [21], which does not permit us to use profile information below approximately $1000 \mathrm{~m}$ height. Our inversion method tends to smooth gradients in the profiles, i.e., values of particle microphysical para- meters may be lower/larger than the true values in height sections where the underlying optical data undergo strong changes within a few height bins [1]. Strong gradients in the optical profiles may thus cause significant errors in the retrieved parameters. A method that allows us to quantify the strength of the gradient above which retrieval errors increase significantly is left for future development work.

\section{Identification of the Origin of Aerosol Plumes}

We used the transport model FLEXPART [28,29] to identify the source region of the plume that was observed over Leipzig and encountered by the aircraft. FLEXPART simulates the long-range transport, dry and wet deposition, and dispersion of air pollutants released from point, line, or volume sources. FLEXPART treats advection, convection, and turbulent diffusion of linear tracers by calculating the trajectories of a multitude of particles that are transported both by the resolved winds and by parameterized subgrid motions [29,30]. For this study, FLEXPART was driven both by global model-level data from the European Centre for Medium-Range Weather Forecasts with a temporal resolution of $3 \mathrm{~h}$, a horizontal resolution of $1^{\circ} \times 1^{\circ}$, and 60 vertical levels, and with data from the National Centers for Environmental Prediction Global Forecast System. FLEXPART was used here in backward mode to identify the sources of sampled air masses. The primary output of the backward simulations is an emission sensitivity identifying the areas where emissions could have affected the sampled air mass. Also important for this study are derived maps of biomassburning source contributions for a carbon monoxide tracer.

\section{Aged Forest-Fire Smoke from North America}

Figure 1 shows a contour plot of the forest-fire smoke plume and the particle backscatter coefficient at $532 \mathrm{~nm}$. The smoke plume extends to approximately $8 \mathrm{~km}$ height above sea level. We see traces of the plume at least up to $9 \mathrm{~km}$ height. The top of the planetary boundary layer is at around $2.5 \mathrm{~km}$ height. Relative humidity drops from around $90 \%$ to $15 \%$ at $3 \mathrm{~km}$ height above sea level.

We carried out FLEXPART simulations for various arrival heights and arrival times of the plume over the lidar site and along the aircraft flight track (see http://www.esrl.noaa.gov/csd/ICARTT/analysis/ index.html). Figure 1 shows an example of the results for the layer arriving $4-5 \mathrm{~km}$ above Leipzig. The column-integrated emission sensitivity shows the pathway of the air mass from boreal North America to Europe. By folding the emission sensitivity map for the lowest model level (not shown) with fire emissions of carbon monoxide estimated by using satellite fire hot-spot data, we derived a source contribution map. This map shows that the smoke plume originated from fires that burned in Alaska and Northwestern Canada about 7-10 days before the measurement. 

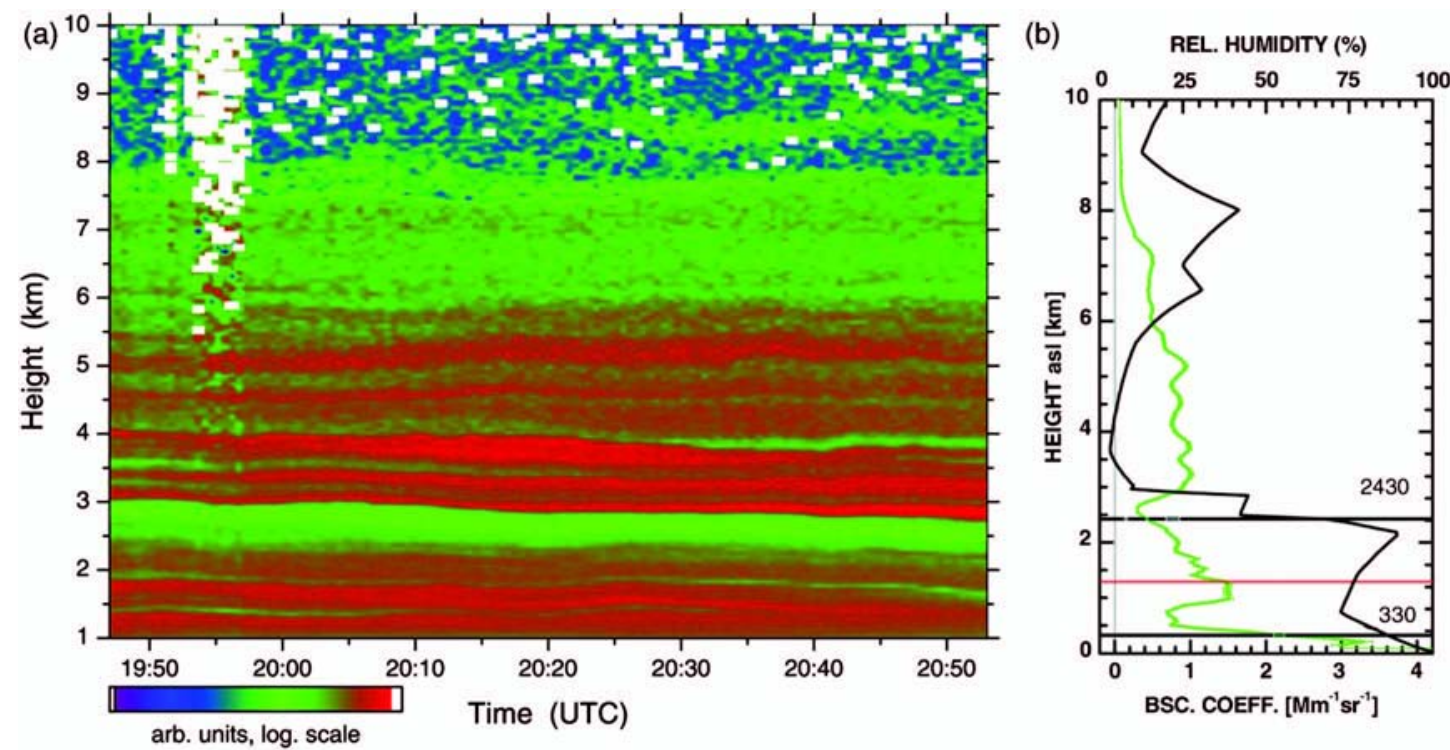

(c)

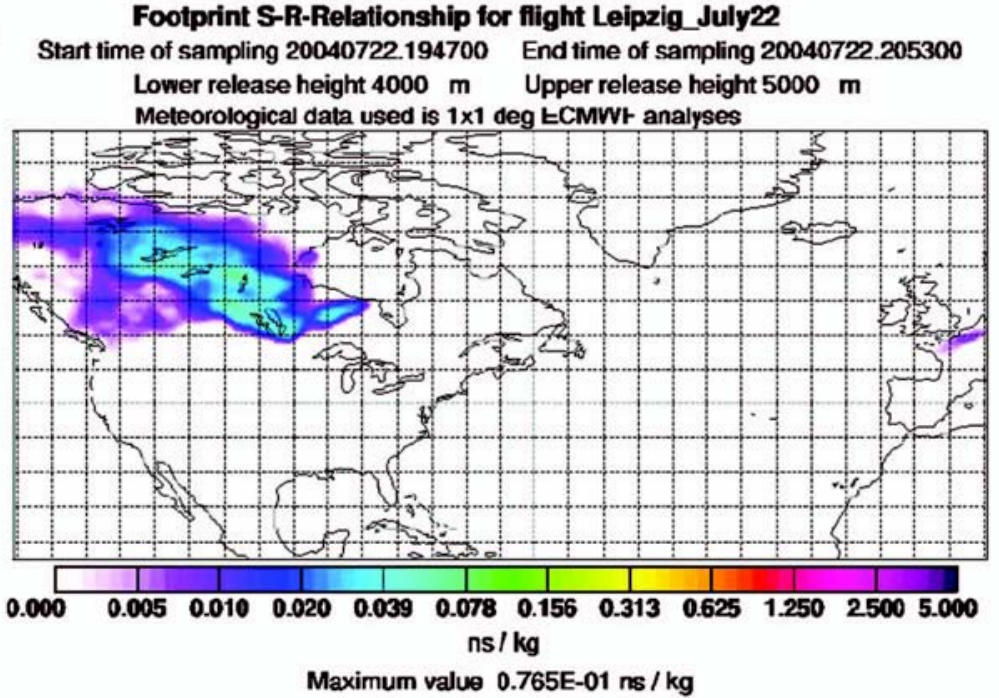

Fig. 1. Measurement at Leipzig on 22 July 2004 from 19:47-20:53 UTC. (a) Time-height plot of the range-corrected backscatter signal at $1064 \mathrm{~nm}$. (b) Particle backscatter coefficient at $532 \mathrm{~nm}$ (smoothing length of $60 \mathrm{~m}$ ). Also shown is the profile of relative humidity. The profile was taken with a radiosonde launched approximately $40 \mathrm{~km}$ to the northwest of Leipzig. Error bars denote 1 standard deviation. (c) Results of "footprint" calculations with FLEXPART. Results are shown for the lidar observation (19:47-20:53 UTC) at Leipzig. The footprint is related to the plume at $4-5 \mathrm{~km}$ over Leipzig. The FLEXPART simulations are provided for the ICARTT campaign by A. Stohl (Norwegian Institute for Air Research, http://www.nilu.no).

We find that the aircraft encountered a portion of the smoke plume that was transported eastward toward the lidar site. We therefore assume that the lidar likely observed a similar part of the smoke layer that was also observed by aircraft, i.e., the source region observed by lidar and aircraft was the same. We certainly cannot expect a perfect agreement of the microphysical and optical properties that are compared in this study. This uncertainty also exists, because the aircraft did not carry a lidar aboard. Thus, we cannot compare the structure (in time and space) of, e.g., the particle backscatter coefficient, which would be a straightforward parameter for quality assurance.
In view of these uncertainties, we expect, at most, comparably good agreement for particle intensive parameters (effective radius, complex refractive index, and single-scattering albedo). In contrast, deviations between inversion and in situ measurements are likely to occur for particle extensive parameters (number, surface-area, and volume concentrations).

Figure 2 shows the profiles of backscatter and extinction coefficients, extinction-to-backscatter (lidar) ratios, and extinction- and backscatter-related Ångström exponents of the smoke plume. We show the smoothed data profiles that were used for the inversion algorithm. In the case of the backscatter profiles, we also show the profiles with less smoothing, 
which thus gives an impression of the vertically varying structure of the biomass-burning layer.

The error bars of the optical data describe the random errors of the lidar signals. The error bars also take into account typical values of the uncertainties due to backscatter calibration, assumption of the Angström parameter, and uncertainties of the temperature and pressure profiles.

The main part of the smoke plume was in the free troposphere. The plume reached a top height of approximately $9 \mathrm{~km}$ above sea level (asl). A typical feature of aged smoke plumes are lidar ratios that are lower at $355 \mathrm{~nm}$ compared to the lidar ratios at $532 \mathrm{~nm}$; see also [26,31,32].

The extinction-related Ångström exponent (355/532 nm wavelength pair) varies between 0.6 and 1 , indicating comparably large particles. For comparison we find values above 1 for anthropogenic pollution from North America [33].

The backscatter-related Ångström exponent at the wavelength pair $532 / 1064 \mathrm{~nm}$ varies between 0.6 and 1 in height above approximately $3 \mathrm{~km}$ asl. The backscatter-related Ångström exponent for the wavelength pair $355 / 532 \mathrm{~nm}$ shows significantly higher values of approximately 2 in the central part of the plume (2.5-5.5 km asl).

The profile of the linear volume (particles+ molecules) depolarization value (not shown) points at particles that are nearly spheres. We find values of $3 \%$ (above $3 \mathrm{~km}$ height asl), which is also characteristic for aged smoke from North America [26]. Furthermore, we often find a comparably low relative humidity in such aged smoke plumes [26]. In the present case, we find values below $25 \%$ in the center of the smoke layer.

Figure 2 also shows the microphysical parameters retrieved with 2 -D regularization. For comparison we also show the results derived with 1-D regularization as described by [1]. The difference between the two methods described therein is that 2 -D regularization uses a smoothing constraint along the vertical dimension, whereas the 1-D regularization does not use this smoothing constraint. That means, in each height bin of the profile, only regularization of the optical data for the respective height bin is done.

The extinction-related Angström exponent (355/532) significantly drops at $6 \mathrm{~km}$ asl. This decrease may either be an artifact that results from processing of the optical data, or a real physical effect. This sudden change of the extinction-related Ångström exponent, in turn, may cause the sudden change of the microphysical parameters around $6 \mathrm{~km}$ height. In this sense, we cannot rule out that the microphysical parameters are affected by significantly larger errors at about $6 \mathrm{~km}$ height than indicated by the error bars. This result calls for further work regarding the characterization of our new methodology, particularly if there are aerosol layers with complicated structure.

Figure 2 finally shows the inversion results if we use the 1-D method in the classical (or traditional) way, as described by $[3,4]$. We selected nine height layers. The height layers are indicated by the vertical error bars in Fig. 2.

In the traditional way of $1-\mathrm{D}$ inversion, we do not invert complete sections of optical profiles. We rather select height layers, for which we average the optical data and from which we compute the microphysical parameters by inversion. We point out that this approach is currently used in all our data inversion, and that this technique of layer selection is one of the reasons for the time-consuming data processing. We show these results from the traditional approach as an example that illustrates the advantage of the new methodology.

If we compare the results for the microphysical parameters we see that the methods of 2-D regularization and 1-D regularization (without vertical smoothing constraint) converge to rather similar results. This result has to be expected in view of the rather smooth optical profiles. However, we see that the classical (traditional) method of our inversion methodology, which uses selected height layers, produces microphysical parameters which in part deviate significantly from the inversion methodology (1-D and 2-D) that uses the profiles. Particularly, we find larger error bars compared to the 1-D and 2-D methods. This higher uncertainty to our understanding is caused by the missing correlation information that is included in an automated manner (intrinsically) in the 1-D and 2-D approaches. In fact, we could also force the results of our traditional methodology to the results that we obtain with the 1-D regularization (without vertical smoothing constraint). In that case, we would need to undergo significant additional work load as we would need to include the correlation information by hand. Correlation information means the following: if optical data, particularly the intensive optical properties, do not change significantly between successive height bins, there is reason to believe that the underlying microphysical parameters (particularly the intensive microphysical properties) also do not change significantly between these successive height bins. This correlation information is used in our 1-D regularization (without vertical smoothing constraint) by the use of a specific averaging procedure [1], which takes into account whole profiles or section of profiles during the postprocessing analysis.

The mean value of effective radius varies around $0.2-0.25 \mu \mathrm{m}$ in the center of the plume. Around $1.5-2 \mathrm{~km}$ height and around $6 \mathrm{~km}$ height, we find a comparably strong increase of particle size. The profiles of number, surface-area, and volume concentrations reach peak values at $4-5 \mathrm{~km}$.

The increase may be caused by a relatively strong increase of relative humidity, which also shows a peak above $6 \mathrm{~km}$ asl (see Fig. 1). However, this new inversion methodology still is in a very exploratory status. We cannot rule out that instabilities of the inversion algorithm in the vicinity of strong gradients 

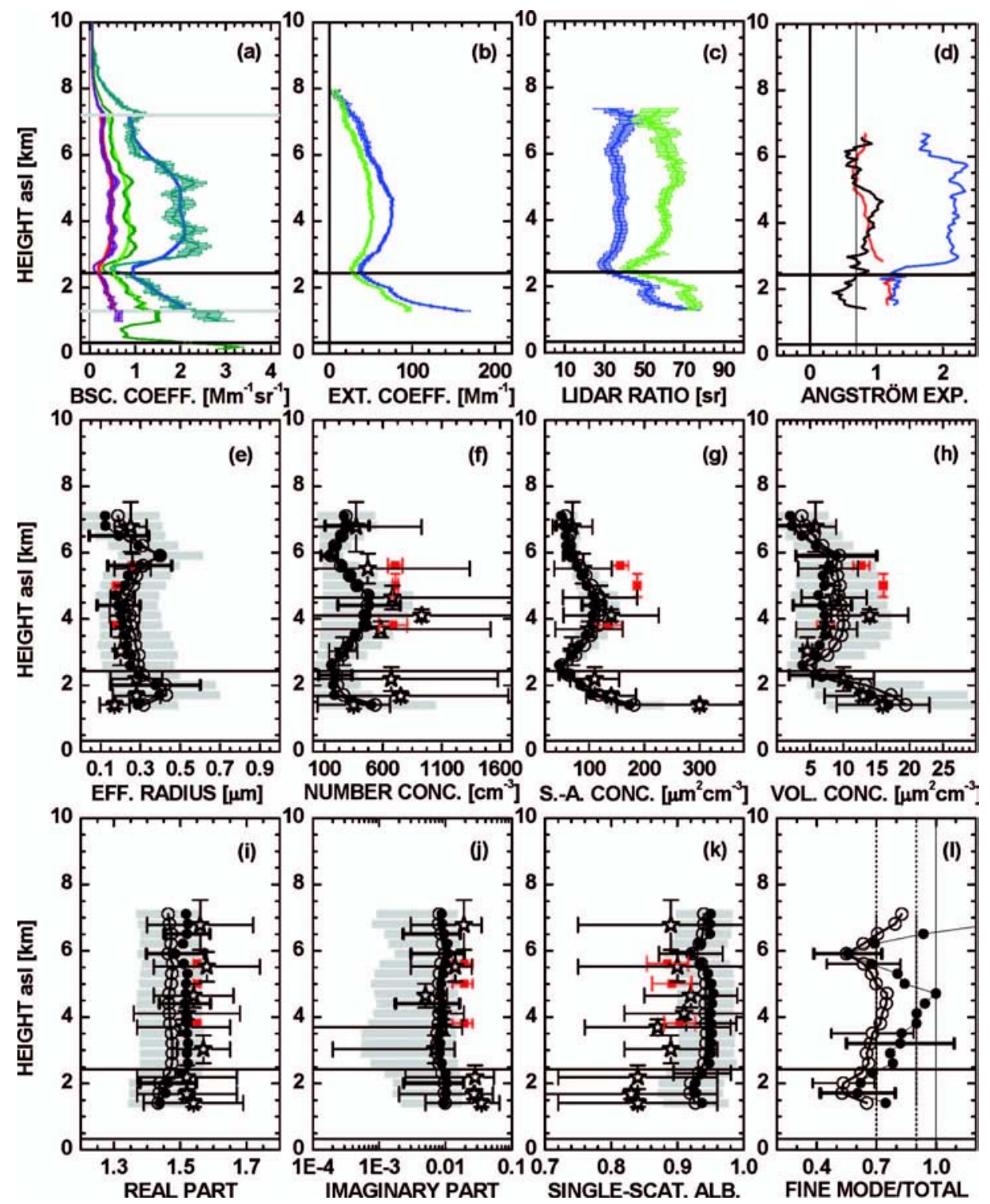

Fig. 2. Measurement at Leipzig on 22 July 2004. Data were taken from 19:47-20:53 UTC. Shown are (a) the particle backscatter coefficients [ 355 (dark blue and light blue), 532 (dark green and light green), and $1064 \mathrm{~nm}$ (red and orange)], (b) the extinction coefficients at 355 and $532 \mathrm{~nm}$, (c) the lidar ratios at 355 and $532 \mathrm{~nm}$, (d) the Angström exponents related to the extinction coefficients (black $=355 / 532 \mathrm{~nm}$ wavelength pair) and the Ångström exponents related to the backscatter coefficients (blue $=355 / 532 \mathrm{~nm}$; red $=532 / 1064 \mathrm{~nm}$ ). Error bars denote 1 standard deviation. In the case of the backscatter coefficients, we show the unsmoothed profiles (vertical resolution of $60 \mathrm{~m}$ ) and backscatter profiles (blue, light green, and red) that were smoothed with the same smoothing length like the profiles of the extinction coefficients; in that case, the vertical resolution is $300 \mathrm{~m}$ up to $2 \mathrm{~km}$ height, $660 \mathrm{~m}$ up to $3 \mathrm{~km}$, and $1260 \mathrm{~m}$ above $3 \mathrm{~km}$. These profiles were used for the data inversion. Results from inversion with 1-D regularization (open circles; gray bars denote 1 standard deviation) and 2-D regularization (bullets; error bars denote 1 standard deviation) present (e) effective radius, (f) number, (g) surface-area, and (h) volume concentrations, (i) the real and (j) the imaginary parts of the complex refractive, (k) single-scattering albedo at $532 \mathrm{~nm}$, and (l) ratio of effective radius below $1 \mu \mathrm{m}$ particle radius to effective radius of total size distribution. We also show the results for nine height layers in which we applied 1-D regularization in the traditional way (stars). The vertical error bars describe the height interval across which the optical input data were averaged. Red boxes show the results from the aircraft observations for three height levels. Measurements took place over Santiago (Spain) from 11:30-16:30 UTC on 22 July 2004. Fire plumes were encountered between 3 and $9 \mathrm{~km}$ altitude. The black horizontal line at $2430 \mathrm{~m}$ indicates the top of the planetary boundary layer.

of the optical profiles cause an artificial increase of particle size.

The error bars in Fig. 2 describe the 2-D regularization method. The gray-shaded bars describe the uncertainty derived with the 1-D methodology. We find errors of $< \pm 50 \%$ in the center of the particle plume. In view of the exploratory status of algorithm development, the magnitude of the uncertainty bars is acceptable. We note that the 2-D regularization methodology, on average, delivers smaller uncertainties than the 1-D methodology. The classical 1-D methodology, if used in the traditional way (layer 
selection), delivers the largest error bars for the investigated parameters.

The real part and the imaginary part of the complex refractive index vary little with height. Error bars are of the order of $5 \%$ for the real part (absolute error of 0.1) for the case of the 1-D regularization methodology. Errors are slightly lower in the case of the 2-D methodology. Uncertainties are approximately $100 \%$ for the imaginary part for both regularization methods. Again, we see that we obtain the largest uncertainties if we use the classical 1-D methodology with layer selection (traditional way).

The column-mean value of the single-scattering albedo at $532 \mathrm{~nm}$ is 0.94 , and the mean error is \pm 0.05 , which is approximately $5 \%$ relative error. A very similar mean value is found with the $2-\mathrm{D}$ regularization methodology. The mean error is slightly lower compared to the 1-D methodology. As before, the largest uncertainties follow from the classical 1-D methodology with layer selection.

As pointed out in Section 1, we aim for an unsupervised data analysis. One flaw of our inversion methodology is that we certainly cannot retrieve the complete coarse mode fraction of the PSD because of the limitations of available measurement wavelengths. The maximum wavelength is $1064 \mathrm{~nm}$, which restricts the retrieval to particle sizes of approximately $3-5 \mu \mathrm{m}$; see also [11].

In the present example of biomass-burning aerosol, we think that this upper particle size limit does not cause too much uncertainty in our retrieval. However, in cases like mineral dust, which is characterized by a significant number concentration of particles in the coarse mode fraction of the PSD, this restriction to $3-5 \mu \mathrm{m}$ will be a major problem.

In this sense, our methodology can be mainly used to infer the fine mode fraction of the PSD. We define the fine mode fraction as that portion of the PSD for which particle radius is less than $1 \mu \mathrm{m}$; see, for instance, [20].

For this reason, we may use the ratio of particle effective radius in the fine mode fraction of the PSD to particle effective radius of the complete PSD (as retrieved by the inversion code) as a quality flag parameter. Figure 2, for example, shows that his ratio, on average, is larger than 0.6 throughout the profile in the case of 1-D regularization. We find values above 0.7 for the case of the 2-D regularization method.

In the ideal case of a value of 1 , this ratio shows us that the retrieved PSD does not contain any particles with radius above $1 \mu \mathrm{m}$, and we can be certain that we do not lose a significant part of the PSD in our unsupervised retrieval. This value of 1 , however, can be reached only theoretically. In practical application, the inversion code will always deliver a certain number of particles above $1 \mu \mathrm{m}$ because of inversion uncertainties and measurement errors.

We point out that we still need to carry out simulation studies that show which value for this ratio is best suited as a flag parameter in the sense of an automated data analysis. In future developments of the inversion methodology, we will use this ratio with respect to number and/or surface-area and/or volume concentration as additional flag parameters.

\section{Comparison to Aircraft Data}

The aircraft data were taken at different flight levels along the western rim of the European continent on 22 and 23 July 2004. The biomass-burning plume was advected from North America to Europe during several days, and we assume that the plume was already well aged when it arrived over Europe. For this reason, we believe that the values of the particle intensive parameters (effective radius, real and imaginary part of the complex refractive index, and single-scattering albedo) did not change significantly between the time and location of the aircraft observations and the time of the lidar observations over Leipzig.

FLEXPART simulations show that the footprints for the aircraft and the lidar observations are rather similar for the observation times and locations of the two measurement platforms. This similarity indicates that lidar and aircraft likely observed a portion of the smoke plume that originated from the same source region. However, as the measurements are not collocated, we cannot expect a perfect agreement for the parameters tested in our study.

Figure 2 shows that the best agreement of the results from the two methodologies (airborne in situ observations and data inversion) is for effective radius. The agreement is better for the case of the 2-D inversion methodology than for the two ways that we applied the 1-D inversion methodology, i.e., in the classical way [3] and without an additional smoothing constraint [1]. Effective radius certainly is the most robust parameter in view of the retrieval uncertainties of the inversion.

We do not expect that the inversion results for the three extensive parameters, i.e., number, surfacearea, and volume concentrations, agree well to the airborne observations because of the lack of collocation of the two instruments. Another reason for disagreement follows from a common problem if we want to compare results from remote sensing and in situ observations. Both methodologies may be sensitive, in terms of received measurement signal, to different particle size ranges. This problem will be discussed further below.

All three extensive parameters from the data inversion tend to be lower than the results from the airborne observations. Unfortunately, the aircraft measured only in three flight levels, which were relatively close together. There seems to be a height dependence of the parameters in these three flight levels. A maximum in volume and surface-area concentration appears around $5 \mathrm{~km}$ height. A similar maximum in the lidar-derived profiles exists a few hundred meters lower. Backward trajectory analysis (not shown here) indicates that the air mass descended by a few hundred meters over west/central 
Europe. In this sense, we may conclude that our lidar inversion algorithm at least catches a similar signature of the extensive parameters. In view of the very sparse data set, this conclusion is speculative. It is obvious that there is strong need for airborne validation studies in which flight levels cover a sufficiently broad altitude range.

Figure 2 shows that the real part (another intensive parameter) from the aircraft measurements is rather close to the inversion results. The third intensive parameter is the imaginary part. The airborne observations result in higher values compared to the numbers that follow from the data inversion. On average, the 2-D inversion methodology delivers slightly better agreement than the 1-D inversion methodology.

The complex refractive index certainly is the parameter with the largest uncertainty in our comparison study. This parameter is difficult to derive from in situ observations. The inversion results are affected with rather high uncertainties. Furthermore, we have no information on how this parameter may change during transport time.

We need to keep in mind that the real part of naturally occurring aerosol particles has a comparably low variability from around 1.35 to approximately 1.7. The imaginary part usually varies between around 0 (nonabsorbing material) to approximately 0.1 (light-absorbing soot mixed with some nonabsorbing compounds). Our inversion retrievals usually have at least $5 \%$ uncertainty in the real part and $50 \%$ in the imaginary part, according to simulation studies carried out in the past 10 years. In this sense, we cannot expect any better agreement to the airborne measurements.

Figure 2 shows results for single-scattering albedo derived from the airborne data. We used the parameters for the PSDs and the complex refractive indices and we computed the single-scattering albedo at $532 \mathrm{~nm}$. Results for single-scattering albedo derived at 440, 550, and $600 \mathrm{~nm}$ are presented by $[23,34]$.

The data products from inversion lead to a higher single-scattering albedo compared to the results from aircraft. This result has to be expected in view of the lower imaginary parts that were derived with the inversion algorithm. The difference is approximately 0.06 , which still is surprisingly low in view of the differences for the imaginary parts (almost a factor 2). We assume that this comparably low difference for the single-scattering albedo is caused by a compensation process. The disagreement for the imaginary part and the real part of the complex refractive index is compensated for by disagreement of the PSD.

Figure 3 shows examples of PSDs obtained from the 2-D inversion; the 1-D inversion shows very similar size distributions. The shape of the PSD cannot be derived with high accuracy due to the limitations of the number of optical data points, the limited range of measurement wavelengths, and lidar measurement uncertainties. Nevertheless, it is worthwhile comparing the PSDs to the in situ measurements. For instance, we expect that, regardless of the uncertainties from data inversion, the aircraft measurements should result in particle concentrations that are larger at smaller particle radii, as we shall explain further below. We present these PSDs for three flight levels of the aircraft.

In both methods (in situ measurements and inversion methodology), we find a rather similar shape of the PSDs. We see that, for two out of the three aircraft flight levels, the peak of the size distribution measured in situ is located at nearly the same particle radius as what the data inversion delivers. In the highest of the three flight levels the inversion methodology shows the maximum value of the PSD at a larger particle radius. The maximum volume concentrations of the PSDs (at the value of the mode radius) measured in situ are considerably higher than the peak values retrieved with the inversion method.

Differences between the PSDs from the two instrument platforms may arise for several reasons. Errors in data inversion may be one reason. The spatial distance of several hundred kilometers is another factor of uncertainty. We also need to keep in mind that the measurement platforms (lidar and aircraft instruments) are sensitive to different size ranges of the investigated PSDs.

The available measurement wavelengths from lidar do not allow us to obtain accurate information on particles with small radii. The minimum measurement wavelength of our lidar system is $355 \mathrm{~nm}$. According to Mie-scattering theory, the strongest sensitivity of light-scattering occurs if particle size is approximately in the range of the sounding wavelength. Thus, we have to assume that the sensitivity of the emitted radiation at $355 \mathrm{~nm}$ with respect to particle size decreases below a particle radius of $100-150 \mathrm{~nm}$.

It is impossible to give an exact number on this lower particle radius, as our inversion methodology

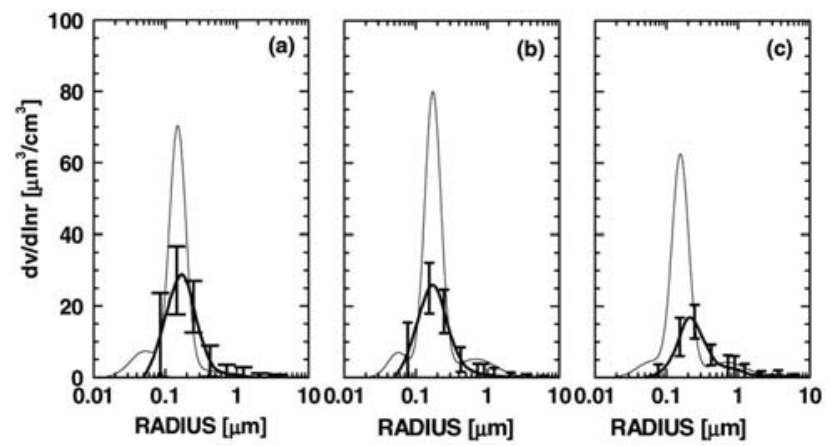

Fig. 3. Examples of three PSDs derived with the inversion methodology (using 2-D regularization) and measured in situ. The PSDs were measured at three flight levels with aircraft (thin curve). The flight levels are (a) $3830 \mathrm{~m}$, (b) $4800-5400 \mathrm{~m}$, and (c) $5730 \mathrm{~m}$. We obtained PSDs from the inversion method (thick curve) for each height level that is marked with a symbol in Fig. 2. The size distributions shown in this figure are the ones nearest to the flight levels, i.e., (a) $3810 \mathrm{~m}$, (b) $5010 \mathrm{~m}$, and (c) $5910 \mathrm{~m}$. 
Table 1. Comparison of Parameters That Describe PSDs in One Flight Level (3830 $\mathrm{m}$ for In Situ and $3810 \mathrm{~m}$ for Inversion) ${ }^{a}$

\begin{tabular}{|c|c|c|c|c|c|c|}
\hline Platform & Radius $(\mu \mathrm{m})$ & $n\left(1 / \mathrm{cm}^{3}\right)$ & $s\left(\mu \mathrm{m}^{2} / \mathrm{cm}^{3}\right)$ & $v\left(\mu \mathrm{m}^{3} / \mathrm{cm}^{3}\right)$ & $r_{\text {eff }}(\mu \mathrm{m})$ & ssa532 \\
\hline \multirow{2}{*}{ Lidar } & {$[0.05-10]$} & 447 & 106 & 7.2 & 0.2 & 0.95 \\
\hline & {$[0.1-10]$} & 274 & 93 & 7.2 & 0.2 & 0.95 \\
\hline \multirow{3}{*}{ In situ } & {$[0.05-1]$} & 686 & 135 & 7.2 & 0.16 & 0.90 \\
\hline & {$[0.05-10]$} & 686 & 135 & 7.3 & 0.16 & 0.9 \\
\hline & {$[0.1-1]$} & 420 & 118 & 6.8 & 0.17 & 0.91 \\
\hline
\end{tabular}

${ }^{a}$ Parameters we computed for two different lower integration limits $(50 \mathrm{~nm}$ and $100 \mathrm{~nm})$ and two upper integration limits $(1 \mu \mathrm{m}$ and $10 \mu \mathrm{m})$. The parameter $n$ describes number concentration, $s$ denotes surface-area concentration, and $v$ describes volume concentration. Effective radius is denoted by $r_{\text {eff. }}$ The single-scattering albedo at $532 \mathrm{~nm}$ is denoted by ssa532.

not only uses this measurement wavelength as input, but also $532 \mathrm{~nm}$ and $1064 \mathrm{~nm}$. Furthermore, we use several constraints in our inversion methodology. We use a smoothness constraint, and a number (respectively volume) concentration of 0 needs to be reached at the lower and upper end of the retrieved PSD. This latter constraint is achieved by using triangles as base functions from which we reconstruct the investigated PSDs [3]. The use of such type of base function naturally leads to an extrapolation of the PSD at the lower and upper ends of the reconstructed particle radius range.

We assume that our methodology provides us with useful information on the PSD for particle radii above $50-100 \mathrm{~nm}$, which, however, cannot be seen as a fixed number for each and every measurement case. This number range must be considered as a soft constraint, as it depends on the specific properties of the investigated PSD, e.g., effective radius and complex refractive index, and measurement errors.

Our assumption on the useful number range of $50-100 \mathrm{~nm}$ also rests upon the rather limited number of simulation studies in which we tried to estimate this lower size limit, e.g., [5]. Finally, this value of $50 \mathrm{~nm}$ was also used in an older study where we compared size distributions from aircraft to inversion results [22].

The comments that are made for the lower particle size range also hold for the upper radius range. According to Mie theory, we have to expect that the maximum sensitivity of the lidar return signal with respect to particle diameter is at around $1 \mu \mathrm{m}$. Keep in mind that the maximum measurement wavelength of our lidar system is $1064 \mathrm{~nm}$. Reference [11] shows that, under most favorable conditions, effective radii of $2 \mu \mathrm{m}$ can be derived. This puts the maximum size range of retrievable particle radii to less than $10 \mu \mathrm{m}$.

Summarizing the above comments, we need to compare the PSDs and, thus, effective radius and the integral parameters, for size ranges for which we believe that both instrument techniques are sensitive. Thus, we investigated the size parameters for different size ranges.

Table 1 shows the results of a sensitivity study in which we computed the parameters of the derived PSDs (shown in Fig. 3) for four different radius ranges, i.e., two different minimum values (50 and $100 \mathrm{~nm})$ and two different maximum values (1 and $10 \mu \mathrm{m})$.

Number concentration from inversion is approximately $50 \%$ lower than the in situ measurements, regardless of the lower and upper limit of particle radius. The deviations between lidar data inversion and in situ measurements of surface-area concentration are approximately $20 \%-30 \%$, and slightly less than $5 \%$ for volume concentration. The percentage difference between in situ and inversion results does not decrease significantly if we use a larger value $(100 \mathrm{~nm}$ instead of $50 \mathrm{~nm})$ for the lower integration limit. The effect is most pronounced for number concentration.

Regarding effective radius, the deviation between in situ and inversion results is approximately $20 \%$. We do not find any significant dependence of the deviation with respect to the lower and upper integration limit. Regarding single-scattering albedo, the dependence on the lower and upper integration limits also is insignificant.

Naturally, number concentration changes significantly if the lower integration limit is increased. Number concentration obtained from the lidar data and from the in situ data decreases by nearly the same amount. In our opinion, this result shows that the choice of the lower integration limit cannot explain the observed deviations of the lidar and in situ derived data.

Regarding the upper integration limit, we do not see any significant changes for number and surface-area concentration and effective radius. Volume concentration from lidar and in situ measurements changes by less than $10 \%$. We consider this change insignificant in view of the overall retrieval uncertainties of the two methods. We do not find any change for single-scattering albedo at $532 \mathrm{~nm}$.

\section{Summary and Outlook}

We present a comparison study of our newly developed method of inversion with 2 -D regularization. This method of 2-D regularization (or smoothing) can be used to infer whole sections of profiles of microphysical properties from the inversion of profiles of optical data acquired with a standard multiwavelength Raman lidar, i.e., backscatter coefficients are 
measured at 355,532 , and $1064 \mathrm{~nm}$, and extinction coefficients are measured at 355 and $532 \mathrm{~nm}$.

PSDs were measured in situ aboard a research aircraft. From these size distributions, we infer particle effective radius and number, surface-area, and volume concentrations. The complex refractive index and single-scattering albedo were derived, too.

We investigated a case of an aged forest-fire smoke plume advected from Canada to Central Europe. For particle effective radius, which is an intensive property, we find very good agreement of the inversion results to the in situ data. Number, surface-area, and volume concentrations, which are extensive parameters, are for the most part lower, compared to the in situ data. These lower values of number, surfacearea, and volume concentrations may be due to errors in our inversion methodology, or inhomogeneities in the pollution plume. The fact that the aircraft did not measure near the lidar site certainly is the biggest disadvantage of our comparison study. However, dilution processes may have caused a decrease of these extensive parameter while the plume traveled across Europe. In this sense, we may not even obtain the same values of the extensive parameters for the two observation sites.

Another intensive particle property compared in our study is the complex refractive index. The data inversion delivers systematically lower imaginary parts, compared to the in situ observations. Regarding the real part, we find similar values from inversion and in situ measurements.

Single-scattering albedo derived from our methodology is consistently larger than what we find from the in situ observations. The uncertainty levels of single-scattering albedo from the inversion methodology are less than 5\%. Within the uncertainty levels, the results from both methodologies are just about the same.

The new methodology, in general, delivers inversion results with considerably less work effort. In addition, data processing speed is higher. We cannot draw a general conclusion on the applicability of the new methodology, as we need many more measurement cases of collocated airborne in situ and groundbased lidar observations. However, we believe that the new methodology can at least be used to infer particle effective radius. Any detailed validation study of this inversion methodology should preferably include aircraft observations at the lidar site.

This work was funded by the Korea Meteorological Administration Research and Development Program under grant CATER 2009-3112. The authors gratefully acknowledge the efforts of the DLR Falcon team during the ICARTT-ITOP experiment in 2004 when the in situ data were collected. Work at the Leibniz Institute for Tropospheric Research was funded by the European Space Agency Support to Science Element (ESA STSE) program ICAROHS under Contract No. 22169/NL/CT.

\section{References}

1. A. Kolgotin and D. Müller, "Theory of inversion with twodimensional regularization: profiles of microphysical particle properties derived from multiwavelength lidar measurements," Appl. Opt. 47, 4472-4490 (2008).

2. D. Müller, U. Wandinger, D. Althausen, I. Mattis, and A. Ansmann, "Retrieval of physical particle properties from lidar observations of extinction and backscatter at multiple wavelengths," Appl. Opt. 37, 2260-2263 (1998).

3. D. Müller, U. Wandinger, and A. Ansmann, "Microphysical particle parameters from extinction and backscatter lidar data by inversion with regularization: theory," Appl. Opt. 38, 2346-2357 (1999).

4. D. Müller, U. Wandinger, and A. Ansmann, "Microphysical particle parameters from extinction and backscatter lidar data by inversion with regularization: simulation," Appl. Opt. 38, 2358-2368 (1999).

5. D. Müller, U. Wandinger, and A. Ansmann, "Microphysical particle parameters from extinction and backscatter lidar data by inversion with regularization: experiment," Appl. Opt. 39, 1879-1892 (2000).

6. D. Müller, U. Wandinger, D. Althausen, and M. Fiebig, "Comprehensive particle characterization from three-wavelength Raman-lidar observations," Appl. Opt. 40, 4863-4869 (2001).

7. I. Veselovskii, A. Kolgotin, V. Griaznov, D. Müller, U. Wandinger, and D. N. Whiteman, "Inversion with regularization for the retrieval of tropospheric aerosol parameters from multiwavelength lidar sounding," Appl. Opt. 41, 3685-3699 (2002).

8. I. Veselovskii, A. Kolgotin, V. Griaznov, D. Müller, K. Franke, and D. N. Whiteman, "Inversion of multiwavelength Raman lidar data for retrieval of bimodal aerosol size distribution," Appl. Opt. 43, 1180-1195 (2004).

9. A. Ansmann and D. Müller, "Lidar and atmospheric aerosol particles," in "Lidar. Range-Resolved Optical Remote Sensing of the Atmosphere," C. Weitkamp, ed. (Springer, 2005), pp. 105-141.

10. C. Böckmann, I. Miranova, D. Müller, L. Scheidenbach, and R. Nessler, "Microphysical aerosol parameters from multiwavelength lidar," J. Opt. Soc. Am. A 22, 518-528 (2005).

11. I. Veselovskii, A. Kolgotin, V. Griaznov, D. Müller, and D. N. Whiteman, "Information content of multiwavelength lidar data with respect to microphysical particle properties derived from eigenvalue analysis," Appl. Opt. 44, 5292-5303 (2005).

12. J. Bösenberg, V. Matthias, A. Amodeo, V. Amoiridi, A. Ansmann, J. M. Baldasano, I. Balin, D. Balis, C. Böckmann, A. Boselli, G. Carlson, A. Chaikovsky, G. Chourdakis, A. Comerón, F. D. Tomasi, R. Eixmann, V. Freudenthaler, H. Giehl, I. Grigorov, A. Hågård, M. Iarlori, A. Kirsche, G. Kolarov, L. Komguem, S. Kreipl, W. Kumpf, G. Larchevêque, H. Linné, R. Matthey, I. Mattis, L. Mona, D. Müller, S. Music, S. Nickovic, M. Pandolfi, A. Papayannis, G. Pappalardo, J. Pelon, C. Pérez, R. M. Perrone, R. Persson, D. P. Resendes, V. Rizi, R. Rocadenbosch, J. A. Rodriguez, L. Sauvage, L. Schneidenbach, R. Schumacher, V. Shcherbakov, V. Simeonov, P. Sobolewsky, N. Spinelli, I. Stachlewska, D. Stoyanov, T. Trickl, G. Tsaknakis, G. Vaughan, U. Wandinger, X. Wang, M. Wiegner, M. Zavrtanik, and C. Zerefos, "EARLINET: a European Aerosol Research Lidar Network to establish an aerosol climatology," Tech. Rep. No. 348 (Max Planck Institute for Meteorology, Hamburg, Germany, 2003).

13. J. Bösenberg, R. Hoff, A. Ansmann, D. Müller, J. C. Antuna, D. Whiteman, N. Sugimoto, A. Apituley, M. Hardesty, J. Welton, E. Eloranta, Y. Arshinov, S. Kinne, and V. Freudenthaler, "Plan for the implementation of the GAW Aerosol Lidar Observations Network GALION,", Tech. Rep. No. 178, WMO/ TD-No. 1443 (World Meteorological Organization, Global 
Atmospheric Watch, Geneva, Switzerland, 2008), http://www .wmo.ch/pages/prog/arep/gaw/gaw-reports.html.

14. Y. M. Noh, Y. J. Kim, and D. Müller, "Seasonal characteristics of lidar ratios measured with a Raman lidar at Gwangju, Korea, in spring and autumn," Atmos. Environ. 42, 22082224 (2008).

15. Y. M. Noh, D. Müller, D. H. Shin, H. Lee, J. S. Jung, K. H. Lee, M. Cribb, Z. Li, and Y. J. Kim, "Optical and microphysical properties of severe haze and smoke aerosol measured by integrated remote sensing techniques in Gwangju, Korea," Atmos. Environ. 43, 879-888 (2009).

16. J. W. Hair, C. A. Hostetler, A. L. Cook, D. B. Harper, R. A. Ferrare, T. L. Mack, W. Welch, L. R. Izquierdo, and F. E. Hovis, "Airborne high-spectral-resolution lidar for profiling aerosol optical profiles," Appl. Opt. 47, 6734-6752 (2008).

17. A. Petzold, M. Esselborn, B. Weinzierl, G. Ehret, A. Ansmann, D. Müller, D. Donovan, G.-J. van Zadelhoff, S. Berthier, M. Wiegner, J. Gasteiger, R. Buras, B. Mayer, D. Lajas, and T. Wehr, "ICAROHS-inter-comparison of aerosol retrievals and observational requirements for multi-wavelength HSRL systems," in Proceedings of the ESA Living Planet Symposium 2010 (European Space Agency, 2010), Special Publication SP686 (CD-ROM).

18. Solutions of Ill-Posed Problems, A. N. Tikhonov and V. Y. Arsenin, eds. (Wiley, 1977).

19. Introduction to the Mathematics of Inversion in Remote Sensing and Indirect Measurements, S. Twomey, ed. (Elsevier, 1977).

20. O. Dubovik and M. D. King, "A flexible inversion algorithm for retrieval of aerosol optical properties from sun and sky radiance measurements," J. Geophys. Res. 105, 20673-20696 (2000).

21. U. Wandinger and A. Ansmann, "Experimental determination of the lidar overlap profile with Raman lidar," Appl. Opt. 41, 511-514 (2002).

22. U. Wandinger, D. Müller, C. Böckmann, D. Althausen, V. Matthias, J. Bösenberg, V. Weiss, M. Fiebig, M. Wendisch, A. Stohl, and A. Ansmann, "Optical and microphysical characterization of biomass-burning and industrial-pollution aerosols from multiwavelength lidar and aircraft measurements," J. Geophys. Res. 107, 8125 (2002).

23. A. Petzold, B. Weinzierl, H. Huntrieser, A. Stohl, E. Real, J. Cozic, M. Fiebig, J. Hendricks, A. Lauer, K. Law, A. Roiger, H. Schlager, and E. Weingartner, "Perturbation of the European free troposphere aerosol by North American forest fire plumes during the ICARTT-ITOP experiment in summer 2004," Atmos. Chem. Phys. 7, 5105-5127 (2007).

24. I. Mattis, A. Ansmann, D. Althausen, V. Jaenisch, U. Wandinger, D. Müller, Y. F. Arshinov, S. M. Bobrovnikov, and I. B. Serikov, "Relative-humidity profiling in the troposphere with a Raman lidar," Appl. Opt. 41, 6451-6462 (2002).

25. A. Ansmann, U. Wandinger, M. Riebesell, C. Weitkamp, and W. Michaelis, "Independent measurement of extinction and backscatter profiles in cirrus clouds by using a combined Raman elastic-backscatter lidar," Appl. Opt. 31, 7113-7131 (1992).

26. D. Müller, I. Mattis, U. Wandinger, A. Ansmann, D. Althausen, and A. Stohl, "Raman lidar observations of aged Siberian and Canadian forest-fire smoke in the free troposphere over Germany in 2003: microphysical particle characterization," J. Geophys. Res. 110, D17201 (2005).

27. Absorption and Scattering of Light by Small Particles, C. F. Bohren and D. R. Huffman, eds. (Wiley, 1983).

28. A. Stohl, M. Hittenberger, and G. Wotawa, "Validation of the Lagrangian particle dispersion model FLEXPART against large scale tracer experiment data," Atmos. Environ. 32, 4245-4264 (1998).

29. A. Stohl and D. J. Thomson, "A density correction for Lagrangian particle dispersion models," Boundary-Layer Meteorol. 90, 155-167 (1999).

30. C. Forster, U. Wandinger, G. Wotawa, P. James, I. Mattis, D. Althausen, P. Simmonds, S. O'Doherty, S. G. Jennings, C. Kleefeld, J. Schneider, T. Trickl, S. Kreipl, H. Jäger, and A. Stohl, "Transport of boreal forest fire emissions from Canada to Europe," J. Geophys. Res. 106, 22887-22906 (2001).

31. I. Mattis, A. Ansmann, U. Wandinger, and D. Müller, "Unexpectedly high aerosol load in the free troposphere over central Europe in spring/summer 2003," Geophys. Res. Lett. 30, 2178 (2003).

32. T. Murayama, D. Müller, K. Wada, A. Shimizu, M. Sekigushi, and T. Tsukamato, "Characterization of Asian dust and Siberian smoke with multi-wavelength Raman lidar over Tokyo, Japan in spring 2003," Geophys. Res. Lett. 31, L23103 (2004).

33. D. Müller, I. Mattis, A. Ansmann, U. Wandinger, C. Ritter, and D. Kaiser, "Multiwavelength Raman lidar observations of particle growth during long-range transport of forest-fire smoke in the free troposphere," Geophys. Res. Lett. 34, L05803 (2007).

34. B. Weinzierl, "Radiatively-driven processes in forest fire and desert dust plumes," Ph.D. dissertation (Ludwig-MaximiliansUniversität München, 2008). 